chronic disease. More psychosocial resources $(\mathrm{OR}=3.57$; 95\% CI:1.33-10.0) were predictive for prolonged work participation in workers with chronic disease only. Age, working hours/week, no functional limitations, depressive symptoms, neuroticism, and sense of mastery were significantly associated with prolonged work participation in workers with and without chronic disease.

Conclusions Predictors of prolonged work participation were similar for workers with and without chronic diseases, except for physical workload and psychosocial resources at work. This implies that differences between workers with and without chronic disease exist, and that these should be taken into account when identifying high risk groups regarding exit from the workforce.

\section{EFFICIENCY OF OCCUPATIONAL HEALTH CO-OPERATION IN SMALL FORESTRY ENTERPRISES}

M S Savinainen, Nyberg, Merivirta. Finnish Institute of Occupational Health, Tampere, Finland

\subsection{6/oemed-2013-101717.31}

In Finland, employers are obligated by law to organise and pay for OHS for their employees. In the agriculture and forestry industry, only $50 \%$ of employers have organised OHS. One reason for this low coverage is that forestry machinery and timber transportation enterprises are usually small. The other, and perhaps the main reason, is that the employers are not familiar with the different tasks of OHS. To assess the efficiency of occupational health co-operation, we need indicators and processes that illustrate co-operation.

Objectives The aim of this study was to clarify how co-operation is carried out, and how it is manifested in the actions of enterprises and occupational health units.

Methods Five forestry machinery and timber transportation enterprises $(\mathrm{n}=5)$ and their OHS units $(\mathrm{n}=5)$ participated in our study. Employers and employee representatives took part in theme group interviews $(\mathrm{n}=5)$ and we interviewed the enterprises' occupational health nurses $(\mathrm{OHN})$ individually $(\mathrm{n}=5)$. We also analysed OHS documents.

Results The interviews revealed that the main OHS tasks were individual work and health check-ups. Real co-operation between enterprises and OHS units was low. Both sides recognised a lack of knowledge concerning the other's work or tasks. Co-operation between enterprise and OHS was rarely mentioned in the various documents. Risks assessments were not carried out, despite being legally obligatory for the enterprises. The main challenges for occupational health co-operation in this field were risk assessments and workplace surveys.

Conclusions In order to improve the effectiveness of occupational health co-operation, the employer and OHS must know each other well, agree on the objectives for their joint actions, and commit to them. Successful co-operation requires regular interaction.

\section{PREDICTORS OF SUCCESSFUL WORK FUNCTIONING}

${ }^{1} \mathrm{~F}$ I Abma, '1 van der Klink, ${ }^{2}$ Amick, 'Bültmann. 'University Medical Center Groningen, Groningen, Nederland; ${ }^{2}$ Institute for Work and Health, Toronto, Canada

\subsection{6/oemed-2013-101717.32}

Objectives To help workers to stay at work in a healthy, productive and sustainable way and to develop interventions to improve work functioning, it is important to have insight in predictors of successful work functioning. The aim of this study is to identify predictors of successful work functioning in the general working population.

Methods A longitudinal study was conducted among the working population. Work functioning was assessed with the Work Role Functioning Questionnaire 2.0 (WRFQ). The total score was categorised as: $0-90 ;>90 \leq 95$; and $>95-100$ (the latter defined as 'successful work functioning'). A stepwise multiple ordinal logistic regression analysis was performed to examine relationships between potential predictors and the dependent variable (successful work functioning). Potential predictors included were mental health, fatigue, decision latitude, work engagement, work ability and baseline work functioning.

Results Mental health $(\mathrm{OR}=1.09$, 95\% Confidence Interval $(\mathrm{CI})=1.02-1.17)$ and fatigue $(\mathrm{OR}=0.93,95 \% \mathrm{CI}=0.88-$ 0.98 ) were both significant predictors of successful work functioning. After the addition of decision latitude and work engagement, only fatigue was predictive of successful work functioning. The effect was attenuated when work ability was added. In the final model, work ability $(\mathrm{OR}=2.07,95 \% \mathrm{CI}=1.22-3.49)$ and baseline work functioning $(\mathrm{OR}=1.16,95 \% \mathrm{CI}=1.07-$ 1.25 ) independently predicted successful work functioning.

Conclusions Work ability and baseline work functioning are predictive for future successful work functioning. However, research has shown that it is difficult to change work ability. The concept of work functioning, reflecting the interplay between work demands and health, might provide better information for the design of interventions.

\section{MEASUREMENT PROPERTIES OF THE 16-ITEM WORK LIMITATIONS QUESTIONNAIRE AMONG INJURED WORKERS WITH MUSCULOSKELETAL DISORDERS - DO DEPRESSIVE SYMPTOMS MAKE A DIFFERENCE?}

${ }^{1} \mathrm{U}$ Bültmann, ${ }^{2}$ Hogg-Johnson, ${ }^{2}$ Lee, ${ }^{3}$ Franche, ${ }^{2}$ Carnide, ${ }^{2}$ Steenstra, ${ }^{2}$ Amick III. ${ }^{1}$ University Medical Center Groningen, Groningen, Nederland; ${ }^{2}$ Institute for Work \& Health, Toronto, Canada; ${ }^{3}$ Vancouver General Hospital, Vancouver, Canada

\subsection{6/oemed-2013-101717.33}

Objectives Little is known about whether the measurement properties of health-related work functioning instruments vary when applied to injured workers with or without depressive symptoms. The objectives of this study are to examine the reliability and validity of the 16-item Work Limitations Questionnaire (WLQ-16) among injured worker's compensation claimants and to explore whether these measurement properties vary by depressive symptom level.

Methods Data were used from the Readiness for Return to Work Cohort Study, a prospective cohort study of Ontario workers filing a Workplace Safety and Insurance Board losttime injury claim for a musculoskeletal disorder. A total of $\mathrm{N}$ $=333$ injured workers who had returned to work were included in the analysis. Thirty-four percent reported a high depressive symptom level (HDSL). The WLQ-16 is designed to assess limitations at work due to physical or emotional health problems or associated treatment. The 20 -item Center for Epidemiologic Studies Depression scale was used to measure depressive symptoms.

Results In HDSL participants, the Cronbach's alphas were markedly lower for time management demands and physical demands when compared to participants with low depressive symptom 